\title{
Alopecia: evaluation and treatment
}

This article was published in the following Dove Press journal:

Clinical, Cosmetic and Investigational Dermatology

18 July 2011

Number of times this article has been viewed

\section{Katherine A Gordon Antonella Tosti \\ Department of Dermatology and Cutaneous Surgery, University of Miami Miller School of Medicine, Miami, FL, USA}

Correspondence: Katherine A Gordon 1600 NW I0th Ave, RMSB Room 2023, Miami, FL, 33136, USA

Tel +l 4077165105

Email kagordon@med.miami.edu
Abstract: Hair loss is a very common complaint. Patients may describe increased shedding and diffuse or localized alopecia. The differential diagnosis of hair loss includes a number of disorders causing cicatricial or noncicatricial alopecias. This paper describes the clinical approaches and diagnostic tests that are useful in the evaluation of patients presenting with alopecia. It also reviews treatments for noncicatricial alopecias, including androgenetic alopecia, alopecia areata, and telogen effluvium, as well as cicatricial alopecias, including lichen planopilaris, its clinical variant frontal fibrosing alopecia, and discoid lupus erythematosus.

Keywords: alopecia, evaluation, treatment

\section{Background}

There are many resources available for the assessment of patients who present with hair loss. Evaluations can be categorized as invasive (eg, scalp biopsies), semi-invasive (eg, trichogram), or noninvasive (eg, hair counts, microscopic evaluation, trichoscopy). Each of the following approaches, when interpreted with the comprehensive clinical picture, can provide valuable insights into patient diagnosis, treatment, and monitoring. ${ }^{1}$ This paper reviews the clinical approaches and diagnostic tests that are useful in the evaluation of patients presenting with alopecia. We reviewed the PubMed literature for evaluative methods and therapeutic interventions for noncicatricial alopecias, including androgenetic alopecia, alopecia areata, and telogen effluvium, and cicatricial alopecias, including lichen planopilaris, its clinical variant of frontal fibrosing alopecia, and discoid lupus erythematosus.

A careful clinical history is essential. In patients complaining of increased hair shedding, clinicians should investigate for potential triggers from the 3 months before the development of hair loss, including drug intake, systemic illness, or weight loss. Gynecologic history is very important in women, and hormonal evaluation is indicated in women with androgenetic alopecia and a history of irregular menses. Further, a family history of hair loss is characteristic in androgenetic alopecia and alopecia areata. Laboratory tests should evaluate iron and vitamin D levels and thyroid function. ${ }^{2}$

Clinical evaluation should establish if hair density is normal or decreased and if the scalp shows diffuse or patchy alopecia. The severity of hair shedding should be assessed by a pull test. The pull test begins with gentle traction on a group of hairs (approximately 40-60) on three separate areas of the scalp. ${ }^{3}$ The hairs extracted by this gentle traction are examined microscopically and quantified. A normal or negative pull test extracts three or fewer hairs and a positive pull test extracts six or more hairs 
from a single area. ${ }^{3}$ Microscopically, the hair roots should be identified as being in the telogen or anagen phase and checked for dystrophy. The telogen roots, which have a club-shaped bulb and an absence of an inner root sheath, are the most commonly seen in a variety of hair disorders. ${ }^{1}$ Dystrophic, broken hairs are seen in diseases that interrupt the mitotic activity of anagen follicles, including alopecia areata and systemic chemotherapy. ${ }^{4}$ Anagen roots, which are darkly pigmented and triangular or delta-shaped, are typically seen in lymphocytic cicatricial alopecia. ${ }^{4}$

The wash test is a valuable tool in which the patient collects hairs shed during standardized shampooing. ${ }^{5}$ In one study, hair was washed and all shed hairs were counted and divided into groups of $5 \mathrm{~cm}$ or longer, intermediate length $(3-5 \mathrm{~cm}$ ), and $3 \mathrm{~cm}$ or shorter (considered telogen vellus hairs). Patients who had at least $10 \%$ telogen vellus hairs were classified as having androgenetic alopecia. ${ }^{6}$ The modified wash test permits evaluation of the whole scalp. One recent study found that dystrophic, anagen hairs were present among the shed telogen hairs in patients with presumed telogen effluvium, who may in fact have alopecia areata incognita. ${ }^{7}$

Trichoscopy, or dermoscopy and videodermoscopy of the scalp, may reveal features of a specific type of hair loss. As an example, in the case of alopecia areata, a characteristic "yellow dot" pattern is often seen, as well as microexclamation hairs and black cadaverized hairs or "black dots" (Figure 1) ${ }^{8,9}$ Dermoscopy in androgenetic alopecia reveals greater than $20 \%$ diversity in the hair diameter (Figure 2). ${ }^{10}$ A brown, depressed halo at the follicular opening can be observed in early androgenetic alopecia and yellow dots can be seen in advanced cases. Further, a honeycomb-pigmented appearance can be appreciated in sun-exposed regions of

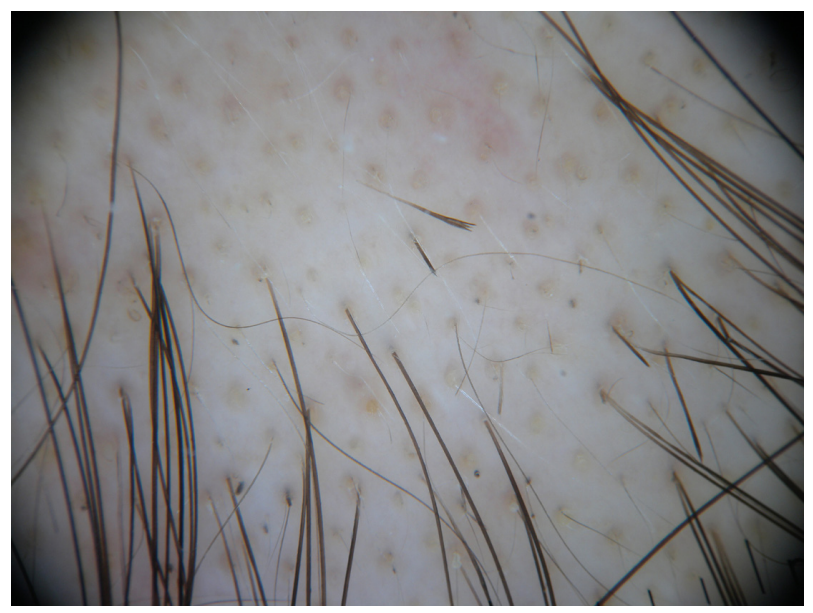

Figure I Alopecia areata: yellow dots and exclamation mark hairs.

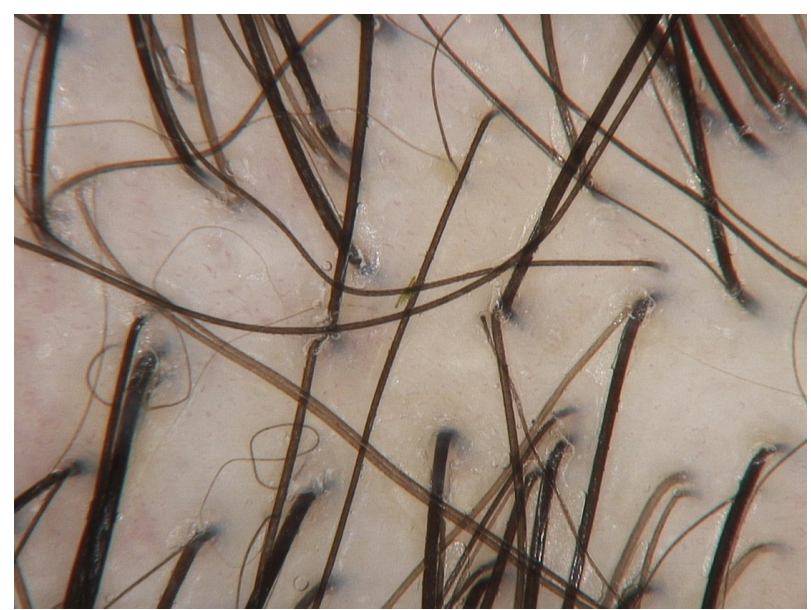

Figure 2 Androgenetic alopecia: hair diameter variability.

the scalp..$^{11}$ Dermoscopy of active lesions of tinea capitis reveals comma hairs, which are slightly curved, fractured hair shafts. ${ }^{9}$

Dermoscopy of primary and secondary cicatricial alopecia reveals decreased hair density and loss of follicular openings (Figure 3). ${ }^{11}$ In the case of lichen planopilaris and its clinical variant, frontal fibrosing alopecia, hyperkeratotic, perifollicular white scales with variable perifollicular erythema and

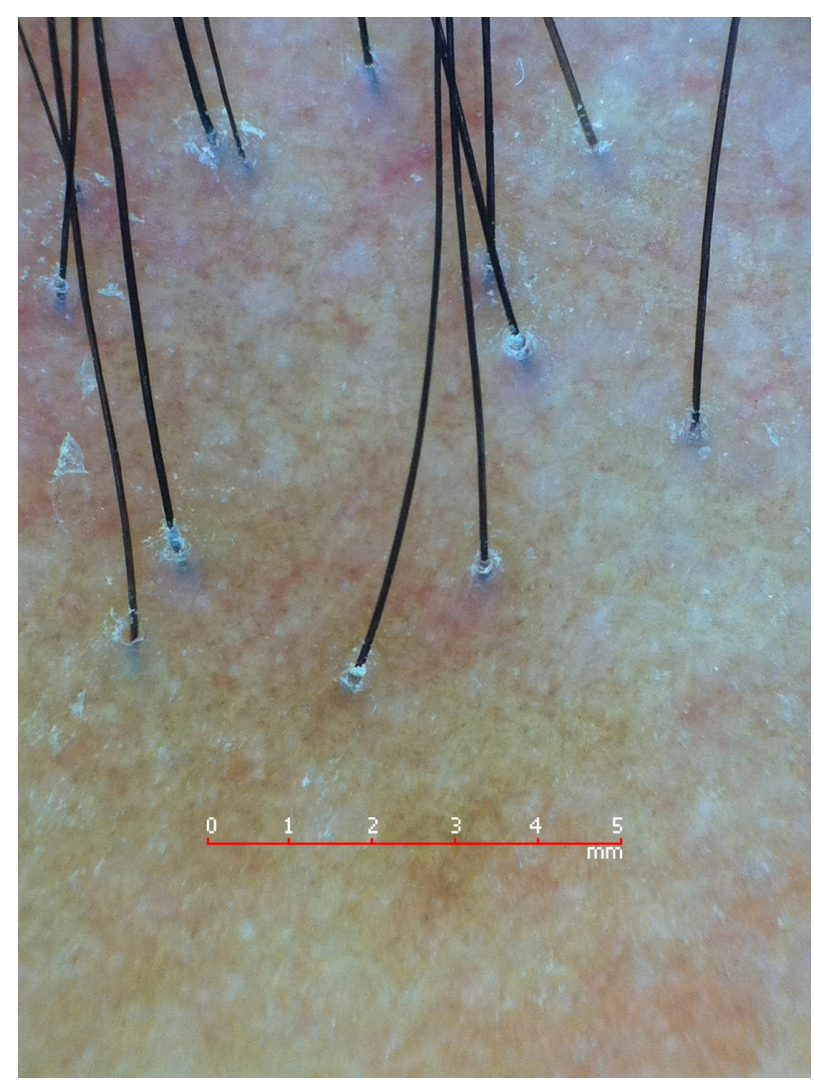

Figure 3 Lichen planopilaris: loss of follicular openings and perifollicular casts. 
peripilar white dots can be observed, ${ }^{10}$ along with blue-gray dots with a target distribution around the follicle. ${ }^{12}$ In the case of discoid lupus erythematosus of the scalp, mottled dyschromia, follicular plugs, telangiectasias, white central plaques, and irregularly distributed blue-gray dots in a speckled pattern between the hair follicles may be seen. ${ }^{11}$ Red dots can help distinguish discoid lupus erythematosus of the scalp from lichen planopilaris. Red dots appear as erythematous, polycyclic, concentric structures, regularly distributed around the follicular opening. ${ }^{13}$ In folliculitis decalvans tufted hairs and perifollicular pustules can be appreciated. ${ }^{11}$

A scalp biopsy (the gold standard is a $4 \mathrm{~mm}$ punch biopsy) can be used for a more definitive diagnosis. ${ }^{14}$ Scalp biopsies can be vertically or horizontally oriented. Vertical or longitudinal punch biopsy is appropriate for the assessment of alopecias associated with interface changes, lichenoid infiltrates, and subcutaneous pathology. ${ }^{15}$ Only portions of a small number of follicular units (2-3) are seen in a given tissue section due to biopsy tangentially interrupting the characteristic angle of hair follicle growth. ${ }^{16}$ Thus, only $10 \%$ of the follicles present in the specimen will be visualized. ${ }^{17}$ Horizontal or transverse biopsy is best taken by a $4 \mathrm{~mm}$ punch biopsy $1-1.5 \mathrm{~mm}$ below the epidermal-dermal junction and yields follicular pathology and a quantitative approach to diagnosis. ${ }^{16}$ Horizontal biopsy also allows complete evaluation of the hair follicles throughout their entire length. ${ }^{17}$

Scalp biopsy is a useful tool for the evaluation of most cases of cicatricial alopecia and some cases of noncicatricial alopecia. The ideal location for biopsy depends on the presumed diagnosis. For example, in noncicatricial alopecia, a punch in the center of the lesion is appropriate; in cicatricial alopecia, the punch should be taken from areas of inflammation. ${ }^{1}$

\section{Androgenetic alopecia}

Androgenetic alopecia, or patterned alopecia, is the most common form of hair loss in both men and women and is characterized by a progressive loss of hair diameter, length, and pigmentation. The genetic inheritance of androgenetic alopecia is well known, although the causative genes have yet to be elucidated. Androgenetic alopecia is often precipitated and exacerbated by conditions that can induce telogen effluvium, including drugs, acute stressors, weight loss, and partum. For example, drugs with androgenetic effects, including contraceptives containing androgenic progestins and hormonal treatments for menopause, may induce or worsen androgenetic alopecia. ${ }^{18,19}$ Due to the progressive nature of androgenetic alopecia, treatments should be started early and extended to maintain efficacy.

Medical treatments approved by the US Food and Drug Administration (FDA) for androgenetic alopecia include topical minoxidil $2 \%$ for women and topical minoxidil $5 \%$ and the oral type II 5- $\alpha$-reductase inhibitor finasteride ( $1 \mathrm{mg} /$ day) for men. ${ }^{20}$ Many authors advocate the use of minoxidil 5\% for women, but this is not approved by the FDA. ${ }^{21}$ The oral type I and II 5 - $\alpha$-reductase inhibitor, dutasteride, is also effective at the dosage of $0.5 \mathrm{mg} /$ day but is not approved for this indication. ${ }^{22}$ Topical minoxidil should be applied twice daily and used for at least 12 months before making a decision regarding efficacy. ${ }^{2}$

Hair transplantation, which is a surgical method of hair restoration, is an option for male and female patients over the age of 25 years with substantial hair loss. The degree and type of hair loss should be considered, because ideal candidates for hair transplantation are those with frontal and midfrontal hair loss. ${ }^{20}$ Follicular unit hair transplantation is the gold standard, because it preserves the natural architecture of the hair units and gives natural results. ${ }^{23}$

The loss of progenitor cells, but not stem cells, is evident in bald vs non-bald scalp areas in patients with androgenetic alopecia. These findings reported by Garza et al support the hypothesis that a defect in conversion of hair follicle stem cells to progenitor cells plays a role in the pathogenesis of androgenetic alopecia. ${ }^{24}$ This breakthrough could implicate a novel model for future treatments.

\section{Alopecia areata}

Alopecia areata is a noncicatricial loss of hair in any area of the body, with a multifactorial autoimmune pathogenesis and an unknown etiology. ${ }^{25}$ This disease affects up to $2 \%$ of the population and presents with a wide range of clinical heterogeneity. ${ }^{26}$ Patients with alopecia areata may present with a very sudden and dramatic loss of hair. Clinically, one or more well circumscribed, smooth, scarless, hairless patches that enlarge in a centrifugal pattern can be observed. Severe forms involve the whole scalp (alopecia areata totalis) or all body hair (alopecia areata universalis). Alopecia areata can be associated with other autoimmune diseases, including thyroid disease, celiac disease, vitiligo, and atopy. ${ }^{27}$

The first episode of alopecia areata can often resolve spontaneously without any medical intervention. ${ }^{27,28}$ The severity of the first episode of alopecia areata is an important prognostic factor. Further, response to topical immunotherapy may be associated with a better prognosis. In children, the 
prognosis is worse. Finally, it has been shown that alopecia areata worsens over time. ${ }^{29}$

Most cases of alopecia areata resolve spontaneously within 1 year, but up to $25 \%$ of patients develop severe forms with total loss of scalp hair (alopecia totalis) or of all body hair (alopecia universalis) that often persist indefinitely. ${ }^{27,28}$ One study showed in adults that the more severe the disease at onset, the more severe the prognosis. In children, the evolution is difficult to predict, because patients with mild alopecia areata also tend to progress to severe forms. ${ }^{29}$

Available treatments may induce hair regrowth but have never been proven to change the course of the disease. These include pulsed high doses of oral or intravenous steroids, topical high potency steroids under occlusion, photochemotherapy, and topical immunotherapy. Efficacy of treatments in patients with alopecia totalis and alopecia universalis is poor, with long-term complete regrowth in less than $20 \%$ of patients. $^{29}$

Intralesional steroids (triamcinolone acetonide $5 \mathrm{mg} / \mathrm{mL}$ ) are probably the most utilized treatments for patchy alopecia areata, although there are no controlled studies that confirm efficacy. ${ }^{28}$ Systemic steroids, which have been used in daily, weekly, and monthly pulse regimens with variable success, are effective in inducing regrowth and arresting hair loss in acute disease. ${ }^{28,30-32}$ However, the use of systemic steroids is limited by the frequent occurrence of relapses after treatment tapering or interruption. ${ }^{28}$ High potency topical corticosteroids under occlusion are also effective in alopecia areata totalis and universalis, with long-term benefit in approximately $15 \%$ of patients. $^{29}$

Topical immunotherapy with diphenylcyclopropenone or squaric acid dibutylester is a good option in severe alopecia, including alopecia totalis and universalis. ${ }^{33}$ The goal of treatment is to induce a mild contact dermatitis of the scalp. The efficacy of diphenylcyclopropenone has been proven by studies that demonstrated hair regrowth limited to the treated half side of the scalp. ${ }^{28,34-36}$ Unfortunately, only a few therapies for alopecia areata have been comprehensively evaluated in randomized controlled trials. ${ }^{37}$

\section{Telogen effluvium}

Telogen effluvium is the loss of telogen hair due to abnormal hair cycling. ${ }^{38}$ Excessive daily shedding of approximately 100-200 telogen hairs is typically seen. If hair loss is present for less than 6 months, it is labeled acute telogen effluvium. However, if hair loss is present for more than 6 months, it is labeled chronic telogen effluvium. ${ }^{2}$ Acute telogen effluvium does not usually produce visible alopecia, because approximately $50 \%$ of hair is usually lost before there is an apparent reduction of hair density. Possible causes of acute telogen effluvium include systemic disease, drugs, fever, psychoemotional stress, weight loss, delivery, iron and Vitamin D deficiency, inflammatory scalp disorders, interruption of oral contraceptives, and iron deficiency. ${ }^{2}$ Treatment for telogen effluvium should be focused on the cause. For example, most dermatologists prescribe iron supplementation when the ferritin level is below $30 \mathrm{ng} / \mathrm{mL}$. However, a recent study showed no statistically significant increase in the incidence of iron deficiency in premenopausal or postmenopausal women with androgenetic alopecia or chronic telogen effluvium vs control subjects. ${ }^{39}$

\section{Cicatricial alopecia}

Cicatricial alopecia includes a group of conditions characterized by inflammation and subsequent destruction of the hair follicle, resulting in irreversible hair loss. Cicatricial alopecia can be primary or secondary. Diseases that primarily affect the hair follicle cause primary cicatricial alopecia, which is classified as lymphocytic or neutrophilic, based on the type of inflammatory cell that predominates. Examples of lymphocytic cicatricial alopecia include lichen planopilaris, its clinical variant frontal fibrosing alopecia, and discoid lupus erythematosus. ${ }^{40}$ Secondary cicatricial alopecia is caused by more systemic disorders, including scleroderma, granulomatous inflammation, such as sarcoidosis, or neoplastic disease. The diagnosis of cicatricial alopecia requires pathological evaluation. Early diagnosis of cicatricial alopecia is essential because the goal of treatment is to slow progression of the condition. $^{41}$

First-line treatments for discoid lupus erythematosus of the scalp and lichen planopilaris are potent topical corticosteroids, including fluocinonide $0.025 \%-0.05 \%$ and clobetasol lotion or cream, ${ }^{42-45}$ and intralesional triamcinolone acetonide $(4-5 \mathrm{mg} / \mathrm{mL}$ and $10 \mathrm{mg} / \mathrm{mL}) .{ }^{46-48}$ Oral corticosteroids ( $1 \mathrm{mg} / \mathrm{kg} /$ day or 25 or $50 \mathrm{mg}$ /day for 1 month) can be particularly helpful in the case of rapidly progressive disease and can be tapered over 2-4 months. ${ }^{48-50}$

Other useful therapeutic options include topical (1.5\%) and oral cyclosporine (4 and $5 \mathrm{mg} / \mathrm{kg} / \mathrm{day}$ for 3-5 months). ${ }^{41,44}$ Hydroxychloroquine was proven effective in arresting progression of lichen planopilaris, frontal fibrosing alopecia, and discoid lupus erythematosus of the scalp. ${ }^{51-53}$ Also, mycophenolate mofetil has been shown to be efficacious in treating lichen planopilaris. ${ }^{54,55}$ Finally, doxycycline has shown some efficacy in the treatment of lichen planopilaris. ${ }^{51}$ 
A promising new treatment focus for lichen planopilaris is the abnormal peroxisome proliferator-activated receptor pathways, which leads to aberrant lipid metabolism in the sebaceous gland, a toxic buildup of lipids, and an inflammatory response. ${ }^{56}$ Improvement of lichen planopilaris following treatment with the oral peroxisome proliferator-activated receptor- $\gamma$ agonist, pioglitazone hydrochloride at $15 \mathrm{mg} /$ day was recently reported. ${ }^{57}$

Overall, an aggressive multiple modality therapeutic approach is often necessary for the treatment of cicatricial alopecia. Unfortunately, treatment failure is common and none of the available agents clearly halt the progression of cicatricial alopecia. ${ }^{58-60}$

\section{Conclusion}

Overall, there are many useful evaluative approaches to aid in the diagnosis of both cicatricial and noncicatricial alopecias. These include scalp biopsies, microscopic evaluation, trichoscopy, or hair counts, just to name a few. Following diagnosis, a variety of treatments are available. Further, promising new treatment modalities are being considered, including those that target hair follicle stem cells for the treatment of androgenetic alopecia or the peroxisome proliferator-activated receptor pathways for the treatment of lichen planopilaris. Continued advances will aid the clinician in effectively treating both cicatricial and noncicatricial alopecias in the future.

\section{Disclosure}

The authors report no conflicts of interest in this work.

\section{References}

1. Dhurat R, Saraogi P. Hair evaluation methods: merits and demerits. Int J Trichology. 2009;1(2):108-119.

2. Tosti A, Piraccini BM, Sisti A, Duque-Estrada B. Hair loss in women. Minerva Ginecol. 2009;61(5):445-452.

3. Hillmann K, Blume-Peytavi U. Diagnosis of hair disorders. Semin Cutan Med Surg. 2009;28(1):33-38.

4. Whiting DA. Histopathology of alopecia areata in horizontal sections of scalp biopsies. J Invest Dermatol. 1995;104(Suppl 5):26S-27S.

5. Whiting DA. Chronic telogen effluvium: increased scalp hair shedding in middle-aged women. J Am Acad Dermatol. 1996;35(6):899-906.

6. Rebora A, Guarrera M, Baldari M, Vecchio F. Distinguishing androgenetic alopecia from chronic telogen effluvium when associated in the same patient: a simple noninvasive method. Arch Dermatol. 2005;141(10):1243-1245.

7. Quercetani R, Rebora A, Fedi M, et al. Patients with profuse hair shedding may reveal anagen hair dystrophy: a diagnostic clue of alopecia areata incognita. J Eur Acad Dermatol Venereol. 2011;25(7):808-810.

8. Ardigo M, Tosti A, Cameli N, Vincenzi C, Misciali C, Berardesca E. Reflectance confocal microscopy of the yellow dot pattern in alopecia areata. Arch Dermatol. 2011;147(1):61-64.

9. Rudnicka L, Olszewska M, Rakowska A, Kowalska-Oledzka E, Slowinska M. Trichoscopy: a new method for diagnosing hair loss. J Drugs Dermatol. 2008;7(7):651-654.
10. Ross EK, Vincenzi C, Tosti A. Videodermoscopy in the evaluation of hair and scalp disorders. J Am Acad Dermatol. 2006;55(5):799-806.

11. Tosti A, Torres F. Dermoscopy in the diagnosis of hair and scalp disorders. Actas Dermosifiliogr. 2009;100(Suppl 1):114-119.

12. Duque-Estrada B, Tamler C, Sodre CT, Barcaui CB, Pereira FB. Dermoscopy patterns of cicatricial alopecia resulting from discoid lupus erythematosus and lichen planopilaris. An Bras Dermatol. 2010;85(2):179-183.

13. Tosti A, Torres F, Misciali C, et al. Follicular red dots: a novel dermoscopic pattern observed in scalp discoid lupus erythematosus. Arch Dermatol. 2009;145(12):1406-1409.

14. Tosti A, Gray J. Assessment of hair and scalp disorders. J Investig Dermatol Symp Proc. 2007;12(2):23-27.

15. Frishberg DP, Sperling LC, Guthrie VM. Transverse scalp sections: a proposed method for laboratory processing. J Am Acad Dermatol. 1996;35(2 Pt 1):220-222.

16. Whiting DA. Diagnostic and predictive value of horizontal sections of scalp biopsy specimens in male pattern androgenetic alopecia. $J \mathrm{Am}$ Acad Dermatol. 1993;28(5 Pt 1):755-763.

17. Stefanato CM. Histopathology of alopecia: a clinicopathological approach to diagnosis. Histopathology. 2010;56(1):24-38.

18. [No authors listed]. Hair loss and contraceptives. Br Med J. 1973;2(5865):499-500.

19. Brache V, Faundes A, Alvarez F, Cochon L. Nonmenstrual adverse events during use of implantable contraceptives for women: data from clinical trials. Contraception. 2002;65(1):63-74.

20. Olsen EA, Messenger AG, Shapiro J, et al. Evaluation and treatment of male and female pattern hair loss. J Am Acad Dermatol. 2005;52(2):301-311.

21. Hoedemaker C, van Egmond S, Sinclair R. Treatment of female pattern hair loss with a combination of spironolactone and minoxidil. Australas J Dermatol. 2007;48(1):43-45.

22. Rathnayake D, Sinclair R. Male androgenetic alopecia. Expert Opin Pharmacother. 2010;11(8):1295-1304.

23. Patwardhan N, Mysore V; IADVL Dermatosurgery Task Force. Hair transplantation: standard guidelines of care. Indian J Dermatol Venereol Leprol. 2008;(Suppl 74):S46-S53.

24. Garza LA, Yang CC, Zhao T, et al. Bald scalp in men with androgenetic alopecia retains hair follicle stem cells but lacks CD200rich and CD34-positive hair follicle progenitor cells. J Clin Invest. 2011;121(2):613-622.

25. Trueb RM. Systematic approach to hair loss in women. $J$ Dtsch Dermatol Ges. 2010;8(4):284-298. German.

26. Kos L, Conlon J. An update on alopecia areata. Curr Opin Pediatr. 2009;21(4):475-480.

27. MacDonald Hull SP, Wood ML, Hutchinson PE, Sladden M, Messenger AG. British Association of Dermatologists. Guidelines for the management of alopecia areata. Br J Dermatol. 2003;149(4):692-699.

28. Alkhalifah A, Alsantali A, Wang E, McElwee KJ, Shapiro J. Alopecia areata update: part II. Treatment. J Am Acad Dermatol. 2010;62(2):191-202.

29. Tosti A, Bellavista S, Iorizzo M. Alopecia areata: a long term follow-up study of 191 patients. J Am Acad Dermatol. 2006;55(3):438-441.

30. Friedli A, Labarthe MP, Engelhardt E, Feldmann R, Salomon D, Saurat JH. Pulse methylprednisolone therapy for severe alopecia areata: an open prospective study of 45 patients. J Am Acad Dermatol. 1998;39(4 Pt 1):597-602.

31. Kar BR, Handa S, Dogra S, Kumar B. Placebo-controlled oral pulse prednisolone therapy in alopecia areata. $J$ Am Acad Dermatol. 2005;52(2):287-290.

32. Sharma VK. Pulsed administration of corticosteroids in the treatment of alopecia areata. Int J Dermatol. 1996;35(2):133-136.

33. Singh G, Lavanya M. Topical immunotherapy in alopecia areata. Int $J$ Trichology. 2010;2(1):36-39.

34. Cotellessa C, Peris K, Caracciolo E, Mordenti C, Chimenti S. The use of topical diphenylcyclopropenone for the treatment of extensive alopecia areata. J Am Acad Dermatol. 2001;44(1):73-76. 
35. Orecchia G, Perfetti L. Alopecia areata and topical sensitizers: allergic response is necessary but irritation is not. $\mathrm{Br} J$ Dermatol. 1991;124(5):509.

36. Dall'oglio F, Nasca MR, Musumeci ML, et al. Topical immunomodulator therapy with squaric acid dibutylester (SADBE) is effective treatment for severe alopecia areata (AA): results of an open-label, pairedcomparison, clinical trial. J Dermatolog Treat. 2005;16(1):10-14.

37. Delamere FM, Sladden MM, Dobbins HM, Leonardi-Bee J. Interventions for alopecia areata. Cochrane Database Syst Rev. 2008;2: CD004413.

38. Harrison S, Sinclair R. Telogen effluvium. Clin Exp Dermatol. 2002;27(5):385-389.

39. Olsen EA, Reed KB, Cacchio PB, Caudill L. Iron deficiency in female pattern hair loss, chronic telogen effluvium, and control groups. J Am Acad Dermatol. 2010;63(6):991-999.

40. Harries MJ, Paus R. The pathogenesis of primary cicatricial alopecias. Am J Pathol. 2010;177(5):2152-2162.

41. Mirmirani P, Willey A, Price VH. Short course of oral cyclosporine in lichen planopilaris. J Am Acad Dermatol. 2003;49(4):667-671.

42. Roenigk HH Jr, Martin JS, Eichorn P, Gilliam JN. Discoid lupus erythematosus. Diagnostic features and evaluation of topical corticosteroid therapy. Cutis. 1980;25(3):281-285.

43. Bjornberg A, Hellgren L. Treatment of chronic discoid lupus erythematosus with fluocinolone acetonide ointment. Br J Dermatol. 1963;75:156-160.

44. Chieregato C, Zini A, Barba A, Magnanini M, Rosina P. Lichen planopilaris: report of 30 cases and review of the literature. Int $J$ Dermatol. 2003;42(5):342-345.

45. Kang H, Alzolibani AA, Otberg N, Shapiro J. Lichen planopilaris. Dermatol Ther. 2008;21(4):249-256.

46. Callen JP. Chronic cutaneous lupus erythematosus. Clinical, laboratory, therapeutic, and prognostic examination of 62 patients. Arch Dermatol. 1982;118(6):412-416

47. Newton RC, Hebert AA, Freese TW, Solomon AR. Scarring alopecia. Dermatol Clin. 1987;5(3):603-618.
48. Ross EK, Tan E, Shapiro J. Update on primary cicatricial alopecias. J Am Acad Dermatol. 2005;53(1):1-37.

49. Kossard S, Lee MS, Wilkinson B. Postmenopausal frontal fibrosing alopecia: a frontal variant of lichen planopilaris. J Am Acad Dermatol. 1997;36(1):59-66.

50. Wiseman MC, Shapiro J. Scarring alopecia. J Cutan Med Surg. 1999;3(Suppl 3):S45-S48.

51. Samrao A, Chew AL, Price V. Frontal fibrosing alopecia: a clinical review of 36 patients. Br J Dermatol. 2010;163(6):1296-1300

52. Kraak JH, Van Ketel W, Prakken JR, Van Zwet W. The value of hydroxychloroquine (Plaquenil) for the treatment of chronic discoid lupus erythematosus; a double blind trial. Dermatologica. 1965;130:293-305.

53. Chiang C, Sah D, Cho BK, Ochoa BE, Price VH. Hydroxychloroquine and lichen planopilaris: efficacy and introduction of Lichen Planopilaris Activity Index scoring system. J Am Acad Dermatol. 2010;62(3):387-392.

54. Cho BK, Sah D, Chwalek J, et al. Efficacy and safety of mycophenolate mofetil for lichen planopilaris. J Am Acad Dermatol. 2010;62(3):393-397.

55. Tursen U, Api H, Kaya T, Ikizoglu G. Treatment of lichen planopilaris with mycophenolate mofetil. Dermatol Online J. 2004;10(1):24.

56. Karnik P, Tekeste Z, McCormick TS, et al. Hair follicle stem cellspecific PPAR gamma deletion causes scarring alopecia. J Invest Dermatol. 2009;129(5):1243-1257.

57. Mirmirani P, Karnik P. Lichen planopilaris treated with a peroxisome proliferator-activated receptor gamma agonist. Arch Dermatol. 2009;145(12):1363-1366

58. Tosti A, Duque-Estrada B. Treatment strategies for alopecia. Expert Opin Pharmacother. 2009;10(6):1017-1026.

59. Tan E, Martinka M, Ball N, Shapiro J. Primary cicatricial alopecias: clinicopathology of 112 cases. J Am Acad Dermatol. 2004;50(1):25-32.

60. Moreno-Ramirez D, Ferrandiz L, Camacho FM. Diagnostic and therapeutic assessment of frontal fibrosing alopecia. Actas Dermosifiliogr. 2007;98(9):594-602.
Clinical, Cosmetic and Investigational Dermatology

\section{Publish your work in this journal}

Clinical, Cosmetic and Investigational Dermatology is an international, peer-reviewed, open access, online journal that focuses on the latest clinical and experimental research in all aspects of skin disease and cosmetic interventions. All areas of dermatology will be covered; contributions will be welcomed from all clinicians and

\section{Dovepress}

basic science researchers globally. This journal is indexed on CAS The manuscript management system is completely online and includes a very quick and fair peer-review system, which is all easy to use. Visit http://www.dovepress.com/testimonials.php to read real quotes from published authors. 